\title{
Reinserção familiar de adolescentes: processos malsucedidos ${ }^{1}$
}

\author{
Aline Cardoso Siqueira ${ }^{2}$ \\ Universidade Federal de Santa Maria, Santa Maria-RS, Brasil \\ Lucianna Tortorelli Massignan \\ Débora Dalbosco Dell'Aglio \\ Universidade Federal do Rio Grande do Sul, Porto Alegre-RS, Brasil
}

\begin{abstract}
Resumo: Este artigo investiga o processo de fracasso na reinserção familiar e a subsequente reinstitucionalização de duas adolescentes. Foram realizados estudos de caso, a partir de entrevistas com as adolescentes e entrevistas informais com técnicos da instituição e monitores. Os resultados indicaram semelhanças nos processos de reinserção, como carência de uma avaliação prévia da situação, considerando a motivação e preparação da família e das jovens para o processo, assim como a falta de um acompanhamento sistemático no período de reinserção. Políticas públicas de atenção a este processo são sugeridas para evitar novas rupturas de vínculos, e para que o direito à convivência familiar e comunitária de jovens institucionalizados possa ser efetivado.
\end{abstract}

Palavras-chave: adolescência, institucionalização, políticas públicas.

\section{Family reintegration of adolescents: unsuccessful processes}

\begin{abstract}
This study investigates the process concerning the unsucessful family reintegration and subsequent re-institutionalization of two adolescents. Case studies were carried out based on interviews with the adolescents and informal interviews with the shelter's technicians and supervisors. The results indicate similarities in the reintegration processes, such as a lack of previous evaluation of the situation, taking into account the family's and the adolescents' motivations concerning the process, as well as a lack of systematic follow-up during the reintegration period. Public policies toward this process are suggested in order to avoid new ruptures of bonds and to ensure the right of institutionalized young individuals to a family life.
\end{abstract}

Keywords: adolescence, institutionalization, public policies.

\section{Reinserción familiar de adolescentes: procesos malogrados}

\begin{abstract}
Resumen: Este estudio investiga el proceso relativo al fracaso en la reinserción familiar y la subsecuente reinstitucionalización de dos adolescentes. Fueron llevados a cabo estudios de caso, por entrevistas con las adolescentes y entrevistas informales con técnicos del abrigo y monitores. Los datos apuntaron semejanzas en los procesos de reinserción, como falta de una evaluación previa de la situación, llevando en cuenta la motivación y preparación de la familia de las jóvenes para el proceso, bien como la falta de un acompañamiento sistemático durante el período de reinserción. Se sugieren políticas públicas de atención a este proceso para evitar nuevas rupturas de vínculos, y para que el derecho a la convivencia familiar y comunitaria de jóvenes institucionalizados pueda ser efectuado.
\end{abstract}

Palabras clave: adolescencia, institucionalización, políticas públicas.

O acolhimento institucional é uma medida de proteção excepcional e provisória, utilizado quando os direitos da criança e do adolescente estão sob ameaça ou são violados. Antes de acionar esta medida de proteção, o Estatuto da Criança e do Adolescente [ECA] (Lei No. 8.069, 1990) dispõe uma série de ações que envolvem as famílias, a comunidade e o poder público em prol da garantia e da defesa dos direitos das crianças e dos adolescentes, sendo o acolhimento institucional a sétima opção (Art. 101, Lei

\footnotetext{
${ }^{1}$ Este texto foi revisado seguindo o Acordo Ortográfico da Língua Portuguesa (1990), em vigor a partir de $1^{\circ}$ de janeiro de 2009. Pesquisa realizada com apoio financeiro do Conselho Nacional de Desenvolvimento Científico e Tecnológico (CNPq) e da Fundação de Amparo à Pesquisa do Estado do Rio Grande do Sul (FAPERGS).

${ }^{2}$ Endereço para correspondência:

Aline Cardoso Siqueira. Rua Floriano Peixoto, 1750/sala 319. CEP 97.015-372. Santa Maria-RS, Brasil.E-mail: alinecsiq@gmail.com
}

No. 8.069, 1990). Apesar de o acolhimento institucional ter caráter excepcional, estima-se que existam mais de 80.000 crianças e adolescentes vivendo em instituições de acolhimento no Brasil (Instituto de Pesquisa Econômica Aplicada, 2003), sendo que cerca de 20.000 estão em entidades conveniadas à Rede de Serviço de Ação Continuada, segundo o Levantamento Nacional de Abrigos (Silva, 2004). Estudos também indicam que o tempo de institucionalização tem sido bastante prolongado, evidenciando a dificuldade em garantir a provisoriedade da medida e a existência de poucos casos em que ocorre a reinserção desses indivíduos em suas famílias (Siqueira, 2009; Siqueira, Betts, \& Dell'Aglio, 2006; Silva, 2004; Weber \& Kossobudzki, 1996). Dessa forma, tendo em vista o expressivo número de casos de crianças e adolescentes institucionalizados e a necessidade de garantir o direito à convivência familiar de forma estável e efetiva, torna-se necessário focalizar o tema da reinserção familiar. 


\section{A legislação}

O ECA (Lei No. 8.069, 1990) apresenta a convivência familiar e comunitária como direito fundamental, reiterando a provisoriedade da medida de proteção de acolhimento institucional. Assim, desde o momento do ingresso de uma criança ou adolescente em uma instituição de acolhimento, deve-se buscar o seu desligamento institucional e a reinserção familiar e comunitária, considerando a particularidade de cada caso.

Segundo a legislação brasileira (Lei No. 8.069, 1990; Lei No. 12.010, 2009), é obrigação da entidade que desenvolve programa de acolhimento institucional favorecer o restabelecimento e a preservação dos vínculos familiares, bem como comunicar às autoridades do Sistema de Justiça, periodicamente, os casos em que se mostre inviável ou impossível o reatamento dos vínculos familiares. Cabe a esta instituição realizar um estudo social e pessoal de cada família, reavaliar periodicamente cada caso, com intervalo máximo de seis meses, dando ciência dos resultados à autoridade competente. Além disso, a Nova Lei Nacional da Adoção (Lei No. 12.010, 2009) estabelece prazo máximo de dois anos de afastamento familiar. Contudo, a questão do tempo de permanência das crianças e adolescentes institucionalizados desafia constantemente os educadores engajados nesse contexto, demonstrando a complexidade dessa medida e a necessidade de inúmeras ações direcionadas tanto às famílias quanto aos órgãos envolvidos, tanto na esfera da assistência social quanto jurídica (Prefeitura Municipal de Belo Horizonte, 2008). O tempo de permanência de uma criança ou adolescente em acolhimento institucional dependerá não só de questões institucionais, mas, principalmente, da superação da situação de risco que motivou o afastamento familiar, geralmente relacionado a inúmeras problemáticas familiares e sociais.

\section{Direito à convivência familiar e comunitária}

A garantia, defesa e promoção do direito à convivência familiar e comunitária são concretizadas nas ações e estratégias de reinserção familiar. Ações de reinserção familiar são aquelas que buscam promover a união de crianças e adolescentes, afastados da família por ameaça ou violação dos seus direitos (Siqueira, 2009). A reunificação familiar é definida não só como a reunião física de crianças e adolescentes que estavam sob cuidados não familiares, com suas famílias de origem, mas também abrange um entendimento mais amplo, enquanto reunificação psicológica. É o processo planejado de reconexão que se dá por meio de uma variedade de serviços e apoio às crianças, aos adolescentes, às suas famílias ou a outras pessoas envolvidas (Maluccio \& Ainsworth, 2003; Pine, Spath, \& Gosteli, 2005).

A temática da reinserção familiar de crianças e adolescentes institucionalizados tem assumido cada vez mais espaço em fóruns e seminários promovidos por entidades de proteção à infância e juventude em situação de institucionalização, embora no campo científico ainda se observe uma carência de estudos no Brasil. Inúmeras formas de nomear este processo têm sido encontradas, como desligamento institucional, desabrigamento, reintegração familiar, desinstitucionalização, retorno à família/convivência familiar, reunificação familiar e reinserção familiar (Azôr \& Vectore, 2008; Siqueira, 2009; Silva \& Nunes, 2004; Siqueira \& Dell'Aglio, 2007). Estas expressões referem-se ao processo de saída da situação de acolhimento institucional e de retorno ao convívio familiar, seja junto à família de origem, extensa ou adotiva.

Os estudos de Azôr e Vectore (2008), Silva e Nunes (2004) e Siqueira (2009) são exemplos de pesquisas sobre este processo no Brasil. Segundo Azôr e Vectore, os fatores que contribuem para o retorno ao convívio familiar de jovens institucionalizados são: insistência do Poder Judiciário, acompanhamento familiar por profissionais, adequação da moradia e desejo dos familiares. O estudo de Silva e Nunes apontou que, após o retorno à família, os jovens acabavam sendo inseridos na situação de vulnerabilidade social na qual seus familiares encontravam-se, com empregos informais e pobre rede social. Siqueira, ao desenvolver um estudo longitudinal com cinco adolescentes em processo de reinserção familiar, constatou uma carência de avaliação, preparação e acompanhamento dos processos pelas instituições responsáveis, além de indicadores de risco nas famílias, tais como precárias condições materiais de vida, família numerosa, desemprego, presença de violência doméstica, entre outros. Para uma efetiva reinserção familiar, além de avaliar as condições socioeconômicas, é necessário conhecer as motivações, o desejo pelo retorno do filho à família e o grau de vinculação existente entre os membros e a criança e/ou adolescente que estão retornando (Azôr \& Vectore, 2008; Siqueira, 2009).

Existem poucos estudos sobre reinserção familiar e sobre reinstitucionalização na realidade brasileira. Entretanto, em outros países, como Estados Unidos, Austrália e países da Europa, as pesquisas sobre estes temas têm sido base para programas de intervenção para famílias há décadas (Courtney, 1995; Festinger, 1996). Apesar das indiscutíveis diferenças culturais e no sistema de bem-estar social de crianças e adolescentes em situação de risco dos diferentes países do mundo, conhecer estudos internacionais é essencial para a compreensão desse fenômeno e para a produção de programas de atendimento adequados para contextos particulares, como o brasileiro.

O estudo de Festinger (1996), desenvolvido na realidade norte-americana, teve por objetivo apontar os fatores de risco familiares, presentes nos processos de reinserção, que poderiam levar à reinstitucionalização, sendo elucidativo para a compreensão desse processo. Esse estudo encontrou como fatores de risco: (1) habilidades parentais pobres; (2) ausência ou pobre apoio social; (3) recusa de serviços externos necessários, como um programa de treinamento de 
habilidades parentais; (4) idade da criança, sendo maior a reincidência de crianças mais velhas. Entre os motivos para o reingresso, estavam: abuso de álcool ou outras substâncias pelos pais, episódios de abuso, negligência e hostilidade direcionados ao filho, dificuldades quanto ao desempenho da parentalidade e recusa da família em realizar tratamento recomendado, como também em receber apoio externo. Courtney (1995) destaca que a taxa de reincidência é mais alta nos primeiros meses de reinserção familiar, sugerindo a necessidade de um programa de acompanhamento especial para as famílias durante este período crítico.

A partir disso, é possível constatar a necessidade de desenvolver estudos que investiguem as dificuldades presentes no processo de reinserção familiar e na permanência de crianças e adolescentes em suas famílias. Assim, o objetivo deste estudo foi compreender o processo de reinserção familiar malsucedido e a subsequente reinstitucionalização do ponto de vista de adolescentes, estudando dois casos em que estes processos foram vivenciados.

\section{Método}

\section{Participantes e local}

Foi realizado um estudo qualitativo, por meio de estudo de casos (Yin, 2003/2005), com adolescentes que estavam acolhidos em instituições de proteção governamentais no estado do Rio Grande do Sul, na modalidade abrigo residencial (AR). Nesta modalidade de acolhimento cerca de 15 crianças e adolescentes são atendidos por monitores que trabalham em turnos, a partir de um atendimento individualizado e semelhante ao contexto familiar (Albornoz, 1998). Os abrigos residenciais participantes deste estudo são chamados informalmente de "casinhas" pelas crianças, adolescentes, monitores e equipe técnica das unidades. Cada unidade é composta por cerca de seis "casinhas", possuindo uma equipe técnica com os seguintes profissionais: psicólogos, educadores, assistentes sociais, pedagogos, enfermeiros, além de estagiários universitários.

As duas adolescentes participantes deste estudo, que serão chamadas pelos nomes fictícios de Juliana e Sabrina, tinham 13 e 14 anos de idade e eram estudantes, respectivamente, da $8^{\mathrm{a}}$ e $5^{\mathrm{a}}$ séries do ensino fundamental de escolas públicas. Sabrina havia retornado para a casa de sua mãe biológica e Juliana para a casa de sua mãe de criação.

\section{Instrumentos}

Foram utilizadas entrevistas com roteiro semiestruturado, diário de campo e o procedimento teórico-metodológico da inserção ecológica (Cecconello \& Koller, 2003; Prati, Couto, Moura, Poletto, \& Koller, 2008). A inserção ecológica possibilitou o acompanhamento mais próximo dos casos e um maior conhecimento sobre o contexto de realização da pesquisa. As entrevistas tinham como temas norteadores o ingresso no acolhimento institucional, as características das famílias, o processo de reinserção familiar, a reinstitucionalização e os planos futuros.

\section{Procedimento}

\section{Coleta de dados}

A coleta de dados foi realizada no período de março a novembro de 2008. As entrevistas individuais com as participantes, após o retorno à instituição de acolhimento, tiveram duração aproximada de uma hora e foram gravadas e transcritas para análise qualitativa. No caso de Juliana, a entrevista foi realizada após três meses de reinstitucionalização, e no caso da Sabrina, após dois meses. Além disso, conversas informais com educadores, monitores e equipe técnica do acolhimento institucional foram realizadas e registradas em um diário de campo. Tais aspectos garantiram a triangulação dos dados.

\section{Análise dos dados}

As entrevistas foram analisadas qualitativamente segundo Yin (2003/2005), a partir de três eixos: (1) processo de desligamento institucional e reinserção familiar; (2) relações familiares e comunitárias; (3) reinstitucionalização. O diário de campo que continha informações apreendidas do contexto do acolhimento institucional, como conversas informais com monitores, assistentes sociais, psicólogos, observações e percepções das pesquisadoras, complementou descritivamente os casos.

\section{Considerações éticas}

Esta pesquisa foi aprovada pelo Comitê de Ética do Instituto de Psicologia da Universidade Federal do Rio Grande do Sul (registro $\mathrm{n}^{\circ}$ 07/007) e pela diretoria técnica do acolhimento institucional. Este estudo consiste no recorte de uma pesquisa maior que teve como objetivo investigar os processos de reinserção familiar de adolescentes institucionalizados. Somente seis adolescentes, com idades entre 12 e 16 anos, foram desligados da instituição durante o período de coleta de dados, sendo que, destes, dois casos não obtiveram êxito no processo e por isso foram selecionados para este estudo sobre o fracasso da reinserção.

Após o aceite da pesquisa pelo responsável da instituição que mantém a guarda dos jovens em acolhimento, as adolescentes selecionadas foram convidadas a participar do estudo e receberam todos os esclarecimentos sobre os procedimentos, o caráter voluntário, a confidencialidade e o sigilo das informações. As adolescentes assinaram Termo de Assentimento. 


\section{Resultados}

\section{Caso 1: Juliana}

Juliana foi institucionalizada em três momentos de sua vida. O primeiro acolhimento institucional ocorreu aos cinco anos de idade, por um período de um ano, por motivo de negligência por parte dos pais. De acordo com técnicos da instituição, sua mãe biológica envolveu-se com prostituição, abandonou a família e faleceu ainda na infância de Juliana. A menina não tinha contato com o pai biológico. Com a ajuda da família de origem de Juliana, uma amiga da família paterna, motivada pelo desejo de ter filhas, procurou o desabrigamento de Juliana e de sua irmã mais nova. Assim, esta senhora tornou-se a mãe de criação de Juliana, assumindo seus cuidados dos seis aos 12 anos de idade, embora sem oficializar juridicamente tal situação. O segundo acolhimento ocorreu quando Juliana estava com 12 anos, a pedido da mãe de criação, em uma instituição governamental em decorrência de seu "mau comportamento". Juliana permaneceu durante nove meses na instituição, sendo reinserida na família da mãe de criação ao final desse período. A última reinstitucionalização, momento em que foi realizado este estudo, ocorreu em decorrência do fracasso desta reinserção, aos seus 13 anos.

\section{Processo de desligamento e reinserção familiar}

Segundo a adolescente, ela e sua irmã visitavam a mãe de criação nos finais de semana, alguns meses antes do desligamento. A equipe técnica não realizou nenhuma visita, antes ou depois do desligamento, à residência da mãe de criação de Juliana. A comunicação entre a instituição e a família dava-se por telefone. Juliana e sua irmã, ao final do ano letivo escolar, foram autorizadas a passar as festas de fim de ano com a mãe de criação, sendo desligadas da instituição após esse período.

\section{Relações familiares e comunitárias}

Após o desligamento, a adolescente passou a morar com a mãe de criação, sua irmã caçula e os três filhos dessa senhora. A mãe de criação e o filho mais velho (24 anos) tinham empregos formais (limpeza e frentista de um posto de gasolina), permitindo que a família possuísse uma casa de alvenaria de dois pisos, oito cômodos e diversos aparelhos eletrônicos. Segundo Juliana, a casa possuía rede elétrica e saneamento básico.

Para a adolescente, as relações familiares eram boas, apesar das brigas que existiam, especialmente entre sua irmã com a sua mãe de criação e o filho de 18 anos, como ela comentou: "a gente se dava bem, só a [irmã] que brigava às vezes com o [irmão de criação de 18 anos]". Contudo, quanto a morar com a mãe de criação, Juliana disse "às vezes foi legal e às vezes foi ruim, porque às vezes teve brigas, mas... foi legal". As brigas aconteciam porque ela e a irmã desobedeciam-na, fazendo-a ficar brava e chateada.

Para Juliana, a pessoa com quem ela mais podia contar era a prima de 12 anos. Segundo a adolescente, "quando eu precisava resolver um problema, ela [prima] me ajudava". Elas eram vizinhas e Juliana costumava ficar horas conversando com a prima, mesmo sem a autorização da mãe de criação, que constantemente aplicava castigos, impedindo que Juliana saísse de casa. Esta situação deixava a adolescente chateada, como pode ser constatado no trecho "uma coisa ruim é que ela [mãe de criação] não deixava a gente sair em lugar nenhum".

\section{Reinstitucionalização}

Juliana foi reinstitucionalizada cerca de cinco meses após a reinserção familiar, a pedido da mãe de criação, juntamente com a irmã (terceira reinstitucionalização). Ela acreditava que o motivo de seu retorno à instituição foi sua desobediência e mau comportamento. Para Juliana, a sua mãe tinha medo de que ela fizesse algo errado na rua, visto que ela restringia as saídas de Juliana de casa. Segundo a diretora da instituição de acolhimento, a mãe de criação percebia semelhanças entre Juliana e sua mãe biológica, julgando que Juliana poderia vir a "puxar" pela sua mãe, que se prostituía para viver.

Juliana regressou ao mesmo AR que estava antes do retorno à família de origem, contudo logo foi transferida para outra "casinha", na mesma região, por decisão da direção da instituição de acolhimento. Segundo a adolescente, esta mudança foi ótima, visto que na antiga "casinha", os monitores "não ajudavam a gente a correr atrás, entendeu? E aqui os tios ajudam a gente". Juliana referia-se aos cursos que passou a realizar depois que mudou de "casinha". Quanto ao sentimento de retornar à instituição, ela contou que, embora no princípio tivesse ficado chateada e triste com a terceira reinstitucionalização, ao longo das primeiras semanas, foi gostando e se adaptando. Afirmou que foi bem recebida pelos amigos e monitores e que estava melhor no acolhimento institucional do que com a mãe de criação. Disse que, na instituição, ela podia fazer passeios e ir aos cursos sozinha, o que a fazia sentir-se mais livre do que quando estava com a mãe. Assim, para ela, os pontos positivos de estar no acolhimento eram poder realizar cursos e ter mais liberdade.

No momento da entrevista, três meses após a reinstitucionalização, a adolescente mantinha contato com a mãe de criação, visitando-a quinzenalmente, novamente sem acompanhamento da equipe da instituição. Quanto ao seu futuro, ela disse: "eu pretendo fazer mais cursos... E depois, quando eu tiver uns 15 anos, fazer um estágio e, bem depois, pensar em voltar pra casa". Não tinha certeza sobre qual profissão seguir. Suas palavras finais, na entrevista, foram: "agora eu tô melhor, quando eu vim pra cá, na hora, eu fiquei triste, mas depois eu fiquei mais feliz... aí foi melhor!’. 


\section{Caso 2: Sabrina}

Sabrina, 14 anos, foi acolhida na instituição aos três anos, juntamente com os irmãos, em decorrência da internação hospitalar da mãe. Tinha uma irmã de 17 anos e um irmão de 11 anos (também em acolhimento institucional com Sabrina), além de um irmão de 24 anos. Ela não conheceu seu pai. Sua mãe era a responsável pela família e, antes da hospitalização, trabalhava como empregada doméstica. Sabrina passou mais de dez anos institucionalizada. Ela recordou que, ao longo desses anos, houve diversas tentativas de morar com a mãe, contudo, não lembrava quando estas tentativas ocorreram e nem o porquê de não terem dado certo. Segundo suas palavras, "a gente ia e voltava, ia e voltava...".

\section{Processo de desligamento e reinserção familiar}

Sabrina visitava a mãe nos finais de semana durante alguns meses antes do desligamento. Contudo, ela não gostava de visitá-la, pois brigavam muito. As visitas não foram acompanhadas por nenhum técnico ou educador da instituição ou pelo Juizado da Infância e Juventude. Pelo contrário, visto que sua mãe vivia numa região violenta e perigosa da cidade, segundo a assistente social da instituição, os técnicos e monitores só podiam acompanhá-la até a entrada da comunidade, sendo que para continuar o caminho, teriam de ter a autorização dos traficantes.

Sabrina e seus irmãos, ao final do ano letivo escolar, foram autorizados a passar as festas de fim de ano com a mãe, sendo desligados da instituição subsequentemente. A equipe técnica não realizou nenhuma visita após o desligamento. Segundo a adolescente, o juiz foi quem determinou o desligamento, e, em sua opinião, sua mãe não sabia da decisão, pois parecia não os estar esperando. Em contato com a equipe técnica do acolhimento institucional, soube-se que, no caso de Sabrina e seus irmãos, houve um "desligamento compulsório", em que o juiz avaliou que a mãe estava em condições de receber a adolescente e seus irmãos, visto que possuía uma casa própria e recebia auxílio da assistência social. A comunicação entre a família e a instituição dava-se por intermédio de Sabrina e sua irmã mais velha. A sua mãe não visitava os filhos na instituição, não tinha telefone e nem mantinha contato com os monitores e equipe técnica.

\section{Relações familiares e comunitárias}

Após o desligamento, a adolescente passou a morar com a mãe, sua irmã de 17 anos e seu irmão de 11 anos. Segundo a adolescente, a casa era pequena, possuía três peças: sala, banheiro e cozinha. Todos dormiam em colchões na sala. Embora a casa fosse pequena e humilde, havia luz e saneamento básico.

Segundo Sabrina, sua mãe tinha problema “dos nervos", tomava vários remédios, apresentava comportamento muito instável, brigava muito com ela e com os irmãos, tendo momentos de descontrole emocional. Seu irmão caçula tinha medo de ficar sozinho com a mãe e, desde pequeno, era muito apegado às irmãs. A irmã mais velha também reagia mal ao comportamento agressivo da mãe, respondendo às agressões, muitas vezes fisicamente, e, segundo Sabrina, esta situação familiar fazia com que a irmã usasse drogas. A comunidade na qual a mãe residia era muito perigosa e controlada por traficantes. Sabrina sentia-se insegura e com medo de andar pela comunidade, afirmando que as pessoas observavam a movimentação e a entrada de desconhecidos. Era comum ouvir tiros durante os dias e as noites, fazendo com que a adolescente se sentisse em estado de alerta.

Um ponto positivo de ter voltado para a casa da mãe, segundo a adolescente, foi a liberdade que ela tinha, especialmente com o namorado, pois podia ir para a casa dele e voltar quando quisesse. Contudo, a violência comunitária que experienciava e a insegurança que sentia com relação à vizinhança foram considerados pontos negativos.

\section{Reinstitucionalização}

Sabrina foi reinstitucionalizada cerca de um mês após a reinserção familiar. Segundo a adolescente, sua mãe e a irmã brigavam muito, em função das más companhias da filha. Após uma briga na qual mãe e filha se agrediram fisicamente, os três irmãos foram ao posto de saúde da comunidade pedir ajuda e, por meio do contato telefônico com a direção da instituição de acolhimento, eles voltaram para lá.

Sabrina retornou ao mesmo abrigo residencial que estava antes do desligamento. Ela afirmou estar feliz por estar de volta, contudo contou que, logo que retornou à "casinha", sentiu-se envergonhada por não ter dado certo. A adolescente afirmou que "na casinha não tem briga, é mais tranquilo, me sinto bem mais... melhor na casinha do que em casa" e "foi bom voltar... aqui eu ganho tudo, né? Tem que aproveitar". Para ela, no acolhimento institucional, ela tinha oportunidades que não teria caso estivesse com a mãe. Sabrina estava realizando um curso de culinária e já sabia fazer bombons, empadinhas, entre outros. No ano anterior, fez um curso de informática. Quanto ao seu futuro, Sabrina comentou que gostaria de estudar mais, fazer mais cursos e ter seu próprio dinheiro. Ela planejava trabalhar num restaurante. Também gostaria de viver em uma comunidade segura, onde não houvesse violência, tráfico e medo.

No momento da entrevista, Sabrina estava realizando novamente visitas à casa da mãe. Segundo a adolescente, ela e os irmãos ficaram algumas semanas sem vê-la, e, posteriormente, visitas de apenas um dia foram liberadas. Acreditava que ela estava mais calma, contudo, caso retornasse novamente, sabia que não daria certo devido à instabilidade emocional de sua mãe.

\section{Discussão}

A reinserção familiar é um processo complexo que exige 
atenção dos agentes sociais envolvidos na garantia, defesa e promoção do direito à convivência familiar e comunitária. Os casos estudados apresentaram informações importantes sobre o processo de reinserção familiar dessas duas jovens em situação de institucionalização. Juliana retornou para a família da mãe de criação, com quem ela viveu durante seis anos, e Sabrina retornou à casa da mãe biológica, com quem não vivia há mais de dez anos. Ambas as famílias eram monoparentais chefiadas pela mãe. A família de Sabrina vivia em condições precárias de vida e de moradia, a mãe não tinha emprego e tinha problemas de saúde mental. Já a família de Juliana tinha melhores condições, proporcionadas pelo fato de a mãe de criação e o primogênito deterem empregos formais e estáveis. Condições precárias de vida e monoparentalidade são descritas na literatura como aspectos presentes nas famílias que têm filhos institucionalizados (Rizzini \& Rizzini, 2004; Silva, 2004; Siqueira, Tubino, Schwarz, \& Dell'Aglio, 2009). Apesar de a monoparentalidade não poder ser tomada como uma variável isolada de outros aspectos, não se pode negar que há uma sobrecarga da figura parental que assume a tarefa tanto de prover o sustento da família quanto de educar os filhos. Por outro lado, o estudo de Yunes, Garcia e Albuquerque (2007) demonstrou a capacidade de superação e de resiliência que famílias monoparentais e de nível socioeconômico desfavorecido possuem, sendo capazes de incentivar e apoiar os filhos.

Em ambos os casos, as adolescentes realizaram visitas nos finais de semana, antes do desligamento, embora sem acompanhamento de técnicos ou educadores da instituição. A literatura tem demonstrado a importância de um plano de visitação para o sucesso da reinserção familiar. O plano deveria ser composto por visitas planejadas, tendo objetivos construídos em conjunto com as famílias. A visitação deve proporcionar reconexão entre o jovem afastado da família e seus familiares, por meio da realização de atividades em conjunto, podendo ser tanto tarefas escolares/domésticas quanto atividades de lazer (Hess \& Proch, 1988; Wright, 2001). Os benefícios que um plano de visitação pode trazer para as crianças e adolescentes são: sentimentos de que os pais/cuidadores os querem na família novamente, elaboração da experiência do afastamento e dos sentimentos acarretados pela separação e a manutenção dos laços familiares. Dessa forma, pode-se constatar que, nos casos analisados, as visitas prévias não operaram como facilitadores, pois ocorreram sem planejamento, objetivos ou atividades conjuntas. Assim, visitas realizadas sem acompanhamento e sem engajamento dos familiares não têm os mesmos resultados que visitas planejadas. Verifica-se a necessidade de promover um melhor planejamento das visitas por meio de um plano de visitação acompanhado por profissionais capacitados, colaborando para a reconexão emocional entre familiares e os jovens e uma interação positiva.

O processo de desligamento institucional também foi semelhante nos casos. Ao final do ano letivo escolar, as meninas e seus irmãos foram autorizados a passar as festas de fim de ano com a mãe, sendo desligados da instituição subsequentemente. No caso de Sabrina, o desligamento foi chamado de "compulsório", a partir da avaliação unilateral do Juizado da Infância e Juventude. O fato de a menina perceber a surpresa da mãe frente ao retorno dos filhos e julgar que ela não tinha conhecimento da decisão é um aspecto importante. Não houve uma investigação substantiva da situação real e atual da família, na qual fosse possível constatar as condições para o retorno da adolescente. Fonseca (2005) destaca que, em busca da efetivação da característica de provisoriedade da medida de acolhimento institucional, muitas instituições promovem a reinserção de crianças e adolescentes em famílias que não têm condições de reassumir a parentalidade dos mesmos. A política da brevidade institucional, que tem por objetivo o desligamento institucional a qualquer custo, segundo Fonseca, é inspirada no desejo de corrigir os erros das políticas de institucionalização do passado que permitiam a institucionalização de crianças e adolescentes por longos períodos. No entanto, esta política pode estar equivocada quando peculiaridades de cada caso não são consideradas no processo de reinserção.

Nos casos estudados, o período após o desabrigamento foi caracterizado por desentendimentos e problemas familiares. A falta de convivência familiar e de conexão emocional entre as adolescentes e suas responsáveis, acabou favorecendo o distanciamento entre as jovens e suas famílias, como consequência da institucionalização. No caso de Sabrina, pode-se perceber um grande distanciamento emocional entre ela e sua mãe, sugerindo ausência de vinculação e conexão entre elas. O comportamento agressivo da genitora e as constantes brigas causavam sofrimento à Sabrina, dificultando o processo de reinserção. Segundo Weber e Kossobudzki (1996), é comum ocorrer afastamento emocional dos pais em relação aos filhos, após um longo processo de institucionalização. No caso de Juliana, a menina descreveu seu relacionamento com a mãe de criação como satisfatório, apesar de relatar constantes conflitos na dinâmica familiar e dificuldade da família em manejar e resolver tais conflitos. A mãe de criação procurava semelhanças entre Juliana e sua mãe biológica, e havia um temor da possível influência genética no comportamento de Juliana. O medo da semelhança entre Juliana e a mãe biológica parecia ser maior do que seu desejo em assumir a parentalidade da menina, levando-a a proibir passeios, mesmo na casa de familiares e em lugares próximos de casa. Estas considerações indicam os aspectos $m a$ crossistêmicos que envolvem as crianças e os adolescentes institucionalizados, presentes na sociedade, como a ideia de que estes jovens têm problemas devido à sua "bagagem biológica" e ao vínculo sanguíneo com seus familiares (Arpini, 2003). Estas crenças podem refletir aspectos do macrossistema que precisam ser considerados pelos técnicos que atuam junto a essa população, de forma que estes valores culturais não impeçam ou dificultem os processos de inserção destes jovens em famílias substitutas ou mesmo em processos de adoção. 
Sabrina percebia que o retorno à família tinha lhe proporcionado mais liberdade, ao passo que para Juliana, na família, sua liberdade foi restringida. Esta clara diferença estava associada às características das famílias das jovens e à sua percepção da instituição. Na família de Juliana, sua mãe de criação restringia sua liberdade como forma de educála, privando a adolescente de realizar atividades típicas da adolescência, como interação entre pares. Na adolescência, inúmeras mudanças físicas, emocionais, cognitivas e sociais ocorrem, exigindo dos jovens adaptações internas adicionais. O processo de tornar-se adolescente envolve a busca de autonomia e de identidade própria (Steinberg, 1999). Estas mudanças relacionadas à puberdade podem fazer com que os adolescentes vivenciem um período de maior vulnerabilidade aos conflitos e problemas cotidianos (Adams, Overholser, $\&$ Spirito, 1994). Pode-se compreender que, durante esta importante fase do ciclo vital, a liberdade é um elemento em destaque, e o posicionamento da mãe de criação refletia uma falta de confiança na adolescente, causando conflitos familiares. Este é um momento crítico também para as famílias, pois elas precisam lidar com as demandas da adolescência, deparando-se com muitas dificuldades e dúvidas quanto ao manejo das situações novas. Assim, tendo em vista a vulnerabilidade que os adolescentes vivenciam nesse período e as dificuldades das famílias em lidarem com esta demanda, a transição entre o contexto institucional e o familiar requer ainda mais atenção, pois pequenos desentendimentos e dificuldades decorrentes das questões relacionadas à adolescência podem exacerbar os problemas e colocar em risco a reinserção familiar.

É possível constatar que conflitos familiares, aliados à falta de apoio social e de segurança, assim como a incerteza quanto ao desejo familiar de retorno da adolescente, fizeram com que, em poucos meses de reinserção familiar, as adolescentes fossem reinstitucionalizadas. No caso de Sabrina e seus irmãos, o retorno ao acolhimento institucional ocorreu após um desentendimento sério entre a mãe e sua irmã; e para Juliana, ocorreu via solicitação da mãe de criação. A melhor situação econômica da família de Juliana não mitigou os riscos presentes no processo de reinserção e nem evitou que ela retornasse ao acolhimento institucional, e a precária condição de vida da família da Sabrina parece não ter sido o grande obstáculo de sua reinserção. Estes aspectos demonstram que o desejo pelo retorno da adolescente e o engajamento no processo, que ocorrem quando os indivíduos estão conectados emocionalmente e sentindo-se pertencentes à família, são aspectos relevantes para o sucesso da reinserção. Segundo Festinger (1996), habilidades parentais pobres e a ausência ou pobre apoio social são aspectos que contribuem para a não manutenção da criança no ambiente familiar. $\mathrm{O}$ caso de Juliana chama a atenção, pois a mãe de criação, que era sua cuidadora desde a infância, "devolveu-a" para a instituição, mesmo tendo assumido o compromisso espontâneo de cuidar dela. Esta postura vai de encontro às determinações do ECA (Lei No. 8.069, 1990) que determina o acolhimento institucional como uma medida de proteção, sendo utilizado quando o jovem está em risco, e não em função da vontade da mãe. Ao permitir a "devolução" da adolescente para a instituição, sem uma avaliação e acompanhamento efetivos, e sem um investimento nas outras opções descritas no ECA (Lei No. 8.069, 1990), o acolhimento institucional contribui para a perpetuação da ideia de instituição como internato e não como uma medida excepcional de proteção.

Outro aspecto comum aos dois casos foi a existência de tentativas anteriores malsucedidas de reinserção familiar, ocasionando rupturas sucessivas de vínculos afetivos. A literatura tem indicado que a ausência de segurança emocional, derivada da falta de relações estáveis na vida da criança, pode levar a problemas no desenvolvimento cognitivo, emocional e social (Bowlby, 1976/1981). Estes importantes aspectos devem ser considerados no planejamento da reinserção familiar, visto que estas falhas podem levar ao fracasso desse processo e a novas rupturas, reforçando tais situações nas trajetórias de vida dessas crianças e adolescentes. Vale destacar, ainda, o posicionamento de Azôr e Vectore (2008) que considera fundamental que o retorno para a família não seja entendido como o final do processo, mas como uma nova etapa que demanda um importante acompanhamento posterior, visando a perceber se a família possui reais condições de acolhimento do jovem.

Por fim, observou-se que as adolescentes apresentavam percepção satisfatória do retorno ao acolhimento institucional. Ambas mencionaram o desejo de ficar na instituição e crescer como cidadãs, "correndo atrás" dos seus desejos e aproveitando as oportunidades que não teriam, caso estivessem com a mãe biológica ou de criação. Embora já estivessem novamente mantendo contato com suas famílias, através de visitas domiciliares, não planejavam retornar à família em curto prazo. Elas apresentavam um desejo de independência, ao planejarem realizar cursos e terem um emprego que lhes remunerasse. Assim, do ponto de vista das adolescentes, a instituição constituía-se num lugar de referência e proteção, lugar este que a família, no momento, não representava. Pode-se perceber que as adolescentes não demonstraram sentimento de pertencimento ao seu grupo familiar e não se sentiam acolhidas ou compreendidas neste espaço. Este posicionamento apresentado pelas participantes pode ser resultado das experiências de vida das meninas, desde a infância, durante a qual elas experienciaram idas e vindas entre família e instituição. Elas consideravam a instituição de acolhimento como fornecedora de apoio tanto instrumental quanto emocional. Estes aspectos contribuíram para que se sentissem pertencentes ao contexto institucional e para que a instituição fosse considerada o melhor lugar para ficar, demonstrando inclusive certa resignação quanto ao fato de não permanecerem junto às suas famílias. 


\section{Considerações finais}

Os resultados deste estudo possibilitaram compreender o processo de reinserção familiar malsucedido e a subsequente reinstitucionalização, a partir de dois casos, demonstrando a complexidade do tema. O ECA (Lei No. 8.069, 1990) preconiza que o acolhimento institucional deve ser de caráter excepcional e provisório, indicando a importância de se pensar na manutenção dos vínculos familiares e em estratégias de reinserção familiar, desde o momento do ingresso do jovem ao acolhimento institucional, garantindo o seu direito à convivência familiar e comunitária.

Foi possível observar, nos casos apresentados, a falta da motivação e de engajamento familiar no processo de reinserção; vínculos afetivos familiares fragilizados; conflitos familiares; relações familiares permeadas por violência física; ausência de confiança na relação entre mãe e filha; ausência de um plano de reinserção que contemplasse a preparação da família e da jovem para o desligamento; falta de uma avaliação da situação familiar tanto emocional quanto financeira; ausência de um acompanhamento próximo durante os primeiros meses de reinserção; e presença de crenças negativas relacionadas às características da família biológica da adolescente.

Considerando que tais aspectos devem ser enfrentados, faz-se necessária a criação de um programa de reinserção familiar composto por uma equipe formada por assistentes sociais e psicólogos, em parceria com a rede de saúde e de assistência social. Estas equipes deveriam desenvolver: (1) avaliação familiar a partir de estudos de caso das famílias, investigando a viabilidade do retorno; (2) preparação das famílias a partir da realização de grupos de apoio às famílias em processo de reunificação familiar, de assessoramento realizado com cada família e do monitoramento e aconselhamento emocional e psicológico, nos momentos dos encontros entre o jovem institucionalizado e sua família. A equipe também promoveria a construção de um plano de reinserção em conjunto com a família, delineando metas para a reunificação, além de um plano de visitas realístico e progressivo; (3) acompanhamento sistemático das famílias com visitas domiciliares frequentes, nos primeiros meses de reinserção familiar, considerado período crítico. Nesse acompanhamento, encaminhamentos necessários para o desenvolvimento da família poderiam ser realizados, como inserção em programas profissionalizantes e tratamento de saúde, por exemplo. Além disso, seria disponibilizada uma escuta das dificuldades enfrentadas no dia a dia pelos familiares e jovens, com vistas a oferecer um suporte e colaborar para a superação desses problemas.

A ausência de planejamento aliada à não realização de visitas domiciliares, após o desligamento e o acompanhamento técnico do processo de reinserção, podem ter influenciado o fracasso do retorno familiar nesses casos. Azôr e Vectore (2008) reiteram a importância da efetivação de políticas públicas eficazes no campo da reinserção familiar, que busquem dar suporte a este processo e aperfeiçoar o atendimento prestado. Destaca-se, ainda, a importância de redobrar a atenção nos casos de reinserção familiar de adolescentes, visto que os jovens estão vivenciando um período peculiar do desenvolvimento que envolve inúmeros processos de transformação e adaptação, exigindo preparação e engajamento extras da família. Assim, também cabe às equipes de acompanhamento disponibilizar informações e apoio às famílias de adolescentes em processo de reinserção familiar.

Finalmente, é importante destacar a limitação do estudo, relacionada à impossibilidade de inclusão dos familiares nas entrevistas realizadas. Faz-se necessário que outras pesquisas sejam realizadas, incluindo os familiares, de forma que possa haver maior triangulação dos dados. Além disso, sugere-se a realização de estudos com amostras maiores e mais diversificadas, compostas por crianças e adolescentes de diferentes faixas etárias e sexo.

É necessário considerar a questão da reinserção familiar com seriedade e maturidade social, evitando a reinstitucionalização. Para isso, é importante organizar políticas públicas que focalizem e privilegiem esse processo, contando com profissionais capacitados e desenvolvendo programas objetivos de reinserção familiar. Também são necessárias pesquisas que avaliem a preparação das famílias e o andamento desses processos, com vistas a compreendê-los de forma integral. As práticas desenvolvidas nas instituições devem ser modificadas, e intervenções consistentes no complexo campo da reinserção familiar precisam ser construídas.

\section{Referências}

Adams, D. M., Overholser, J. C., \& Spirito, A. (1994). Stressful life events associated with adolescent suicide attempts. Canadian Journal of Psychiatry, 39(1), 43-48.

Albornoz, A. C. G. (1998). Os efeitos preventivos e curativos dos cuidados parentais substitutos com relação à doença mental grave: Fundamentando a práxis. Aletheia, 1(7), 27-33.

Arpini, D. M. (2003). Violência e exclusão: Adolescência em grupos populares. Bauru, SP: EDUSC.

Azôr, A. M. G. C. C. V., \& Vectore, C. (2008). Abrigar/ desabrigar: Conhecendo o papel das famílias nesse processo. Estudos de Psicologia (Campinas), 25(1), 77-89.

Bowlby, J. (1981). Cuidados maternos e saúde mental. São Paulo: Martins Fontes. (Original publicado em 1976)

Cecconello, A. M., \& Koller, S. H. (2003). Inserção ecológica na comunidade: Uma proposta metodológica para o estudo de famílias em situação de risco. Psicologia: Reflexão e Crítica, 16(3), 515-524.

Courtney, M. E. (1995). Reentry to foster care of children returned to their families. Social Service Review, 69(2), 226-241.

Festinger, T. (1996). Going home and returning to foster care. Children and Youth Services Review, 18(4/5), 383-402. 
Fonseca, C. L. W. (2006). Conexões intergeracionais em famílias acolhedoras: Considerações sobre tempo e abrigagem. Praia vermelha: Estudos de Politica e Teoria Social, 13(1), 154-173.

Hess, P. M., \& Proch, K. O. (1988). Family visiting in out-ofhome care: A guide to practice. Washington, DC: Child Welfare League of America Press.

Instituto de Pesquisa Econômica Aplicada. (2003). Levantamento nacional dos abrigos para crianças e adolescentes da rede de Serviço de Ação Continuada (SAC): Relatório de Pesquisa número 01. Brasília, DF: IPEA. Recuperado em 14 julho 2009, de http://www. mp.rs.gov.br/areas/infancia/arquivos/abrigos.pdf

Lei No. 8.069, de 13 de julho de 1990. (1990, 16 de julho). Dispõe sobre o Estatuto da Criança e do Adolescente e dá outras providências. Diário Oficial da União, seção 1.

Lei No. 12.010, de 3 de agosto de 2009. (2009, 3 de agosto). Dispõe sobre adoção; altera as Leis Nos. 8.069, de 13 de julho de 1990 — Estatuto da Criança e do Adolescente, 8.560, de 29 de dezembro de 1992; revoga dispositivos da Lei No. 10.406, de 10 de janeiro de 2002 — Código Civil, e da Consolidação das Leis do Trabalho - CLT, aprovada pelo Decreto-Lei No. 5.452, de $1^{\circ}$ de maio de 1943; e dá outras providências. Recuperado em 9 de março de 2010, de http://www.planalto.gov.br/ ccivil_03/_Ato2007-2010/2009/Lei/L12010.htm

Maluccio, A. N., \& Ainsworth, F. (2003). Drug use by parents: A challenge for family reunification practice. Children and Youth Services Review, 25(7), 511-533.

Prati, L. E., Couto, M. C. P. P., Moura, A., Poletto, M., \& Koller, S. H. (2008). Revisando a inserção ecológica: Uma proposta de sistematização. Psicologia: Reflexão e Crítica, 21(1), 160-169.

Pine, B., Spath, R., \& Gosteli, S. (2005). Defining and achieving family reunification. In G. P. Mallon \& P. M. Hess (Eds.), Child welfare for the twenty-first century: A handbook of practices, policies, and programs (pp. 378391). New York: Columbia University Press.

Prefeitura Municipal de Belo Horizonte. Secretaria Municipal Adjunta de Assistência Social. (2008). Projeto político educativo para entidades de abrigo: Marco orientador das relações. Belo Horizonte: $\mathrm{PBH} / \mathrm{SMAAS}$.

Rizzini, I., \& Rizzini, I. (2004). A institucionalização de crianças no Brasil. Rio de Janeiro: Ed. PUC-RJ.

Silva, E. R. A. (Coord.). (2004). O direito à convivência familiar e comunitária: Os abrigos para crianças $e$ adolescentes no Brasil. Brasília, DF: IPEA/CONANDA.

Silva, M. R. S., \& Nunes, K. S. (2004). Avaliação e diagnóstico do processo de reinserção familiar e social de crianças e adolescentes egressos de uma casa de passagem. Cogitare Enfermagem, 9(1), 42-49.

Siqueira, A. C. (2009). Crianças, adolescentes e transições ecológicas: Instituições de abrigo e família como contextos de desenvolvimento. Tese de doutorado não publicada, Universidade Federal do Rio Grande do Sul, Porto Alegre.
Siqueira, A. C., Betts, M. K., \& Dell'Aglio, D. D. (2006). A rede de apoio social e afetivo de adolescentes institucionalizados no Sul do Brasil. Revista Interamericana de Psicologia/Interamerican Journal of Psychology, 40(2), 149-158.

Siqueira, A. C., \& Dell'Aglio, D. D. (2007). Retornando para a família de origem: Fatores de risco e proteção no processo de reinserção de uma adolescente institucionalizada. Revista Brasileira de Crescimento e Desenvolvimento Humano, 17(3), 134-146.

Siqueira, A. C., Tubino, C. L., Schwarz, C., \& Dell'Aglio, D. D. (2009). Percepção das figuras parentais na rede de apoio de crianças e adolescentes institucionalizados. Arquivos Brasileiros de Psicologia, 61(1), 176-190.

Steinberg, L. (1999). Adolescence. New York: McGrawHill.

Weber, L. N. D., \& Kossobudzki, L. H. M. (1996). Filhos da solidão: Institucionalização, abandono e adoção. Curitiba: Governo do Estado do Paraná/Secretaria da Cultura.

Wright, L. E. (2001). Toolbox No. 1: Using visitation to support permanency. Washington, DC: Child Welfare League of America Press.

Yin, R. K. (2005). Estudo de caso: Planejamento e métodos (2a ed.) D. Grassi, Trad. Porto Alegre: Bookman. (Original publicado em 2003)

Yunes, M. A. M., Garcia, N. M., \& Albuquerque, B. M. (2007). Monoparentalidade, pobreza e resiliência: Entre as crenças dos profissionais e as possibilidades da convivência familiar. Psicologia: Reflexão e Crítica, 20(3), 444-453.

Aline Cardoso Siqueira é Professora Doutora do Departamento de Psicologia da Universidade Federal de Santa Maria.

Lucianna Tortorelli Massignan é Psicopedagoga e Especialista em Psicologia Clínica com ênfase em Saúde Comunitária pelo Instituto de Psicologia da Universidade Federal do Rio Grande do Sul.

Débora Dalbosco Dell'Aglio é Professora do Programa de Pós-graduação em Psicologia da Universidade Federal do Rio Grande do Sul.
Recebido: $28 / 01 / 2010$

$1^{a}$ revisão: $17 / 04 / 2010$

$2^{a}$ revisão: $16 / 08 / 2010$

$3^{a}$ revisão: 21/01/2011

Aceite final: 10/03/2011 